\title{
High pressure water-washing to remove pests from capsicums
}

\author{
L.E. Jamieson, N.E.M. Page-Weir, A. Chhagan, S. Olsson, P.G. Connolly, \\ R.M. McDonald and A. Woolf \\ The New Zealand Institute for Plant E Food Research Limited (Plant E Food Research), \\ Private Bag 92169, Auckland, New Zealand \\ Corresponding author: Lisa.Jamieson@plantandfood.co.nz
}

\begin{abstract}
Removal of pests on export fruit before packing using high pressure water-washing is used commercially in New Zealand for apples and avocados and has the potential to be extended to other fruits and vegetables. Mealybugs, thrips and mites are intercepted on exported capsicums and the presence of species of quarantine importance results in methyl bromide fumigation, which disrupts export, reduces fruit quality and is costly. The removal of mealybugs from naturally infested capsicums was measured after high pressure waterwashing at 50,75, 100, 125, 150, 175 or 200 psi and compared with results from an untreated control. Before treatment, capsicums had an average of 12-37 live mealybugs per fruit. At 3 days after high pressure water-washing, the numbers of live mealybugs on treated capsicums ranged from 3.8 to 11.8 per fruit, resulting in $58-85 \%$ reduction. This compared with an average of 44 mealybugs on untreated capsicums at 3 days after treatment.
\end{abstract}

Keywords mealybugs, removal, high pressure, water-washing.

\section{INTRODUCTION}

Removal of pests on export fruit before packing using high pressure water-washing is used commercially in New Zealand for apples and avocados. The moderately high pressure, high water volume system used in apples washes fruit for 10-20 seconds using multiple nozzles operating at pressures between 80 and 120 psi orientated straight down on multiple banks (rows) of manifolds while fruit move over rotating brushes. This procedure is based on overseas systems that were developed for removal of pests from citrus and apples (Honiball et al. 1979; Walker et al. 1996, 1999) and disease reduction and cleaning up apples (Bai et al. 2006). This treatment is applied to nearly all exported apples in New Zealand and achieves up to $90 \%$ removal of mealybug as well as reductions in woolly apple aphid, scale, apple leafcurling midge, mites, leafrollers and a range of hitchhikers such as weevils and spiders, without causing apple damage (J.T.S. Walker, Plant \& Food Research, unpublished data).

Another very high pressure (500-900 psi), low water volume system has been commercially implemented for avocados. This system individually aligns fruit, which are treated with a short (1 second), high pressure treatment (500-900 psi), with two rotations of the fruit under jets from three directions (Whiting 1998a, b; McDonald 1999; Jamieson et al. 2000), and does not rely on a prolonged period of semi-random movements of fruit used by the 
moderately high pressure, high water volume system. Two avocado packhouses have been running very high pressure, low water volume washing for the last decade; others have recently installed units, and nearly all packhouses will have units this season, as it is now a requirement for avocados entering the USA. However, the very high pressure, low water volume avocado system is more technically challenging than the moderately high pressure, high water volume apple system and tends to have lower throughput and higher capital and running costs (larger pumps), which is why the moderately high pressure, high water volume system is used for washing large volumes of apples.

High pressure water-washing has the potential to be extended to other fruit and vegetables. New Zealand growers produce 7000 tonnes p.a. of capsicums valued at \$NZ30 million for export to Japan and Australia. The presence of mealybugs, thrips, mites and psyllids can cause market access issues and the presence of species of quarantine importance results in costly methyl bromide fumigation, which also reduces out-turn quality of capsicums. The storage and shelf life of capsicums is limited by visual wilt and infections affecting the stem, calyx and/or fruit body. Currently fungicidal dips are used as a standard commercial postharvest treatment for fungal infection.

Non-chemical postharvest disinfestation treatments are being sought and high pressure water-washing is one possible solution. A significant advantage of treatments that remove insects compared with those that simply kill insects is that the absence of insects on arrival in overseas markets means the product line is much more likely to move promptly through the importing border inspection systems.

This study reports on the feasibility of using moderately high pressure, high water volume system to remove mealybugs from capsicums using a similar system to that used for apple exports, but with nozzles orientated at alternating $45^{\circ}$ angles to target the stem area.

\section{METHODS}

Capsicums (cultivar 'Funky') were sourced from areas of a commercial glasshouse with high insect levels. Fruit naturally infested with longtailed mealybugs (Pseudococcus longispinus), New Zealand flower thrips (Thrips obscuratus) and mites (two-spotted mite, Tertranychus urticae, and predatory mites, various species) were harvested and transported to Plant \& Food Research, Auckland, where they were individually numbered and examined under a microscope one day before treatment. The number of mealybugs, thrips and mites and their location on the fruit were recorded and fruit were assigned randomly to treatments and placed in trays at $20^{\circ} \mathrm{C}$. The numbers of thrips and mites were too low and variable; therefore only reductions in numbers of mealybug were assessed.

Groups of 10 infested capsicums were treated for $15 \mathrm{~s}$ at one of seven pressures $(50,75,100,125$, 150, 175 or 200 psi) using an experimental Plant \& Food Research water-washer. Untreated control fruit were used as a comparison. There were three replicates for each treatment and control and each replicate treatment was carried out separately. Capsicums were left to air dry and then repacked into trays inside insect proof bags and placed at $20^{\circ} \mathrm{C}$ until assessment.

The experimental water-washer (a smallscale replica of the standard commercial apple washers) was similar to that described by Walker et al. (1996). The system consisted of a gantry of nozzles positioned over a brush bed of eight rotating scalloped rollers. The length of rollers under the gantry was $1140 \mathrm{~mm}$ long by $900 \mathrm{~mm}$ wide. The gantry had eight transverse rows of nozzles, with each row $120 \mathrm{~mm}$ apart. On each row, six nozzles (160 mm apart) were set up with the tip of the nozzles $150 \mathrm{~mm}$ above the brush bed. In order to improve insect removal of the stem and distal end of the fruit (which tend to align on their sides on the brush bed), each row of nozzles was oriented at $45^{\circ}$ (laterally), with each row alternating the direction (left then right). The nozzles were Promax ${ }^{\circledR}$ QPTA, 40/15 (Spraying Systems Company USA patent 6398128). Flow rate was 7, 9 and 11.2 litres/min for 50, 100 and 150 psi. Fruit were fed into the system using a roller infeed and were then moved along by other fruit, to achieve a treatment time of 15 seconds.

Capsicums were examined under a microscope 3 days after treatment and the number of 
mealybugs remaining and their location on the fruit were recorded.

\section{Statistical analyses}

Comparisons of percentage mealybug reduction at different locations, where appropriate, were made by using the Generalized Linear Model procedure (Chambers \& Hastie 1992) in R ( R Development Core Group 2009) version 2.10.1. The model assumed that the variance was proportional to that of a binomial distribution, with allowance for the over-dispersed nature of the data.

\section{RESULTS AND DISCUSSION}

Before treatment, naturally infested capsicums had a mean of 20 live or 23 total (live plus dead) mealybugs per fruit (Table 1). It was difficult to assess mealybugs in a non destructive manner in the cavity under the stem; therefore, the pre-treatment numbers may have been underestimated. The capsicums were selected for the trial by commercial quality control staff because they had unusually high mealybug infestations, which presented a greater challenge for reducing infestation using high pressure water-washing than normal commercial 'pest loading' on exported capsicums. At the post treatment assessment 2-3 days later, the numbers of live and total mealybugs on untreated capsicums had increased to 44 and 45 per fruit, respectively because of the production of numerous young nymphs from the adults present. This is represented by a 'negative' percent reduction in Table 1.

In contrast, after high pressure water washing there were $58-84 \%$ live and $62-83 \%$ total (live plus dead) fewer mealybugs than pre-treatment. This is an underestimate of actual percentage removal as it includes young nymphs produced by surviving adults post treatment. The percentage reduction from the entire capsicum was similar to that at the stem, where approximately $87-91 \%$ of mealybugs were located. The mealybugs that remained on the stem-end tended to be beneath the calyx. The remaining $3-8 \%$ of the mealybugs found at either the cheek or calyx included mealybugs able to wander from the stem to these locations on the fruit and were quite variable. On some of the treated capsicums, the numbers of mealybugs on the cheek or calyx increased from pre- to post-treatment, probably because the mealybugs

Table 1 Mean number of live (and total) mealybugs per capsicum and percentage reduction after waterwashing from all the capsicum and at different locations on the fruit.

\begin{tabular}{|c|c|c|c|c|c|c|}
\hline \multirow{2}{*}{$\begin{array}{l}\text { Treatment } \\
\text { pressure } \\
\text { (psi) }\end{array}$} & \multicolumn{2}{|c|}{ Mean number/capsicum } & \multicolumn{4}{|c|}{$\%$ removal } \\
\hline & $\begin{array}{c}\text { Pre- } \\
\text { treatment }\end{array}$ & $\begin{array}{c}\text { Post- } \\
\text { treatment }\end{array}$ & Total & Stem & Cheek & Calyx \\
\hline untreated & $20(23)$ & $44(45)$ & $-54(-48)^{1}$ & $-58(-55)^{1}$ & $51(65)$ & $-58(-54)^{1}$ \\
\hline 50 & $12(14)$ & $4(4)$ & $68(70)$ & $68(70)$ & $33(47)^{2}$ & $64(64)$ \\
\hline 75 & $37(40)$ & $12(13)$ & $58(62)$ & $58(61)$ & $20(23)^{2}$ & $58(68)$ \\
\hline 100 & $31(36)$ & $4(7)$ & $85(80)$ & $85(79)$ & $93(97)$ & $70(66)$ \\
\hline 125 & $29(32)$ & $6(7)$ & $76(74)$ & $74(72)$ & $98(95)$ & $81(77)$ \\
\hline 150 & $24(29)$ & $7(10)$ & $69(68)$ & $68(66)$ & $93(90)$ & $64(62)$ \\
\hline 175 & $27(30)$ & $4(5)$ & $84(83)$ & $82(81)$ & $100(100)$ & $88(88)$ \\
\hline 200 & $22(27)$ & $6(7)$ & $73(75)$ & $72(71)$ & $94(98)$ & $42(39)^{2}$ \\
\hline P-value & & & $0.104^{3}$ & $0.250^{3}$ & -4 & -4 \\
\hline
\end{tabular}

${ }^{1}$ negative $\%$ s refer to the $\%$ that were not present before treatment.

${ }^{2}$ values calculated by averaging positive and "negative removal" percentages.

${ }^{3}$ comparing all treatments except the control (untreated).

${ }^{4}$ treatments on cheek and calyx locations could not be analysed in the same way, because positive and negative components are not comparable. 
remaining beneath the calyx, or their progeny had moved to that location after treatment. There were no significant differences between water pressures in the percentage reduction of mealybugs from the entire capsicum.

Fruit quality trials will be required to determine the optimum pressure of a commercial high pressure water-washing treatment of capsicum. Preliminary data showed damage to the fruit, particularly the stems, at above 100 psi. A high pressure water-washing treatment using 75 psi followed by a 30 -second hot water drench at $55^{\circ} \mathrm{C}$ (a heavy shower of hot water) and hot air drying resulted in better quality capsicums than the standard commercial treatment dipping in a fungicide (Olsson et al. 2009).

Many export markets are moving away from a single 'silver bullet' disinfestation treatment to a systems approach that involves methods of quantitative pest risk analyses. This approach assesses the impact of a range of mitigation measures along a pathway whereby, if combined, mitigation measures can demonstrate that the final probability of a commodity arriving at its destination infested with a quarantine pest remains below an 'acceptable allowable limit'. If after this defined process, the probability remains below the threshold, the commodity is allowed entry to the market.

\section{CONCLUSION}

High pressure water-washing using water pressures between 50 and 200 psi reduced live mealybugs by $58-84 \%$, while numbers of live mealybugs on untreated controls doubled over the trial period. High pressure water-washing has the potential to be utilised in a systems approach to improve access for New Zealand capsicums to current and new export markets.

\section{ACKNOWLEDGEMENTS}

Thanks to New Zealand Hothouse for fruit supply and The New Zealand Foundation for Research, Science and Technology (Contract C06X0709) for funding.

\section{REFERENCES}

Bai J, Mielke EA, Chen PM, Spotts RA, Serdani M, Hansen JD, Neven LG 2006. Effect of high-pressure hot-water-washing treatment on fruit quality, insects, and disease in apples and pears: Part I. System description and the effect on fruit quality of d'Anjou' pears. Postharvest Biology and Technology 40(3): 207-215.

Chambers JM, Hastie TJ 1992. Statistical Models in S. Wadsworth and Broods/Cole, Pacific Grove, California.

Honiball F, Giliomee JH, Randall JH 1979. Mechanical control of red scale (Aonidiella auranti Mask) on harvested oranges. Citrus and Subtropical Fruit Journal 549: 17-18.

Jamieson L, Whiting DC, Woolf AB, White A, McDonald RM 2000. Water-blasting avocados to remove leafroller eggs. New Zealand Plant Protection 53: 371-374.

McDonald RM 1999. NZ Pat. 314528 "Washer".

Olsson S, O’Donogue E, Brummell D, Jamieson L, McDonald R, Woolf A 2009. Effect of high pressure water-washing and hot water drench on postharvest quality of capsicums. Postharvest Pacifica 2009, Australasian Postharvest and Managing Quality in Chains Conference, 15-19 November 2009, Napier, New Zealand. p. 123.

R Development Core Team 2009. R: A language and environment for statistical computing. $\mathrm{R}$ Foundation for Statistical Computing, Vienna, Austria. ISBN 3-900051-07-0, http:// www.R-project.org.

Walker G, Morse N, Arpaia ML 1996. Evaluation of a high-pressure washer for postharvest removal of California red scale (Homoptera: Diaspididae). Journal of Economic Entomology 89(1): 148-155.

Walker G, Zareh N, Arpaia ML 1999. Effect of pressure and dwell time on efficiency of a high-pressure washer for postharvest removal of California red scale (Homoptera: Diaspididae) from citrus fruit. Journal of Economic Entomology 92(4): 906-914. 
Whiting DC, Hoy LE, Connolly PG, McDonald RM 1998a. Effects of high-pressure water jets on armoured scale insects and other contaminants of harvested kiwifruit. Proceedings of the 51st New Zealand Plant Protection Conference: 211-215.
Whiting D, Hoy L, Maindonald J, Connolly P, McDonald R 1998b. High-pressure washing treatments to remove obscure mealybug (Homoptera: Pseudococcidae) and lightbrown apple moth (Lepidoptera: Tortricidae) from harvested apples. Journal of Economic Entomology 91(6): 1458-1463. 